\title{
Взаимосвязь между атмосферным выпадением азота, наземной растительностью и почвами в лесах Ижевска
}

\author{
И. Ю. Кудреватых ${ }^{1}$, Г. Р. Платунова ${ }^{2}$ \\ ${ }^{1}$ Институт физико-химических и биологических проблем почвоведения РАН, \\ Российская Федерация (142290, Московская обл., г. Пущино, ул. Институтская, д.2., стр.2) \\ 2 Удмуртский государственный университет, Российская Федерачия \\ (426034, г. Ижевск, ул. Университетская, 1)
}

\begin{abstract}
Аннотация: Цель - изучить атмосферные выпадения минерального азота $\left(\mathrm{N}_{\text {мин }}\right)$ в лесах промышленного региона для оценки взаимосвязи между его поступлением, изменением свойств почв и структуры наземной растительности.

Mатериаль и методы. На территории города Ижевск и Завьяловского района Удмуртской Республики были изучены хвойные и лиственные леса $(\mathrm{n}=21)$ на дерново-подзолистой почве. Исследования проводились на основе оценки атмосферных выпадений $\mathrm{N}_{\text {мин }}$ методом снегосъемки, опробования почв из гумусо-аккумулятивного горизонта и геоботанического описания растительности. В образцах снега и почв определяли содержание нитратов и аммония. В почве дополнительно определяли содержание общего углерода и азота, $\mathrm{P}_{2} \mathrm{O}_{5}, \mathrm{Cd}, \mathrm{Pb}, \mathrm{Zn}, \mathrm{Cu}, \mathrm{Ni}$ и $\mathrm{pH}$. Взаимосвязь между изученными параметрами оценивали с помощью анализа главных компонент.

Результаты и обсуждение. Атмосферные выпадения $\mathrm{N}_{\text {мин }}$ на территории исследования варьировали от 0,15 до 20,6 кг га/год, в которых преобладала аммонийная форма. Анализ главных компонент показал корреляционную взаимосвязь между атмосферным выпадением $\mathrm{N}_{\text {мин }}$, содержание в почве $\mathrm{N}^{-\mathrm{NO}_{3}}$, $\mathrm{P}_{2} \mathrm{P}_{2} \mathrm{O}_{5}, \mathrm{Cd}, \mathrm{Pb}, \mathrm{Zn}, \mathrm{Cu}, \mathrm{Ni}$ и баллом по экологической шкале обеспеченности почв минеральным азотом Г. Элленберга.
\end{abstract}

Ключевые слова: леса, загрязнение азотом, напочвенный покров, химические свойства почв.

Источник финансирования: Работа выполнена в рамках гос. задания № 0191-2019-0048.

Для цитирования: Кудреватых И. Ю., Платунова Г.Р. Взаимосвязь между атмосферным выпадением азота, наземной растительностью и почвами в лесах Ижевска // Вестник Воронежского государственного университета. Серия: География. Геоэкология, 2021, № 2, с. 3-12. DOI: https://oi.org/10.17308/ geo.2021.2/3441

\section{ВВЕДЕНИЕ}

За последние 200 лет численность населения и связанная с ним потребность в природных ресурсах привели к увеличению антропогенного загрязнения такими поллютантами как сера $(\mathrm{S})$ и азот $(\mathrm{N})$. Отмечают, что в последние несколько десятилетий атмосферные выпадения $\mathrm{S}$ уменьшились или, по крайней мере, стабилизировались, в то время как выпадения N, по-прежнему имеют тенденцию к увеличению [27].

По данным Доклада о состоянии и охране окружающей среды Удмуртской Республики (УР) выбросы оксидов азота $\left(\mathrm{NO}_{\mathrm{x}}\right)$ от совокупных (стационарных и передвижных) источников каждый год увеличиваются и в 2016 году они составили 17,2 тыс. т. [5]. В настоящее время концентрация $\mathrm{NO}_{\mathrm{x}}$ в воздухе превышает ПДК во всех районах города Ижевска, а выпадения минерального азота $\left(\mathrm{N}_{\text {мин }}\right)$ из атмосферы на территории УР составляет 2-7 кг на га в год (2014-2015 гг.) [5]. Исследования показали, что деревья в 2-3 раза лучше «поглощают» соединения загрязнителей из атмосферы по сравнению с травянистой и кустарничковой растительностью [3]. Учитывая, что лесистость города Ижевска и Завьяловского района составляет $37 \%$, существуют экологические риски для лесов, которые расположены в зоне высокой антропогенной эмиссии $\mathrm{N}_{\text {мин }}$.

(С) Кудреватых И. Ю., Платунова Г.Р., 2021

\ Кудреватых Ирина Юрьевна, e-mail: averkieva.irina@yandex.ru

Контент доступен под лицензией Creative Commons Attribution 4.0 License. 
Оценке экологических эффектов для природных лесов, которые связаны с увеличением выпадений $\mathrm{N}_{\text {мин }}\left(\geq 20\right.$ кг ${\mathrm{N} \mathrm{ra}^{-1} / \text { год }}^{-1})$ посвящены многие исследования в Западной Европе, США, Канаде и Китае [13, 16, 20, 22]. В них показано, что при повышении атмосферных выпадений $\mathrm{N}_{\text {мин }}$ происходит изменение химических свойств почвы в сторону эвтрофикации (увеличение питательных элементов) и/или подкисления, которые влияют на перестройку видов в напочвенном покрове лесов $[11,12,15,26,28]$. По общемировым прогнозам отмечается, что выпадения соединений азота вместе с деградацией земель и климатическими изменениями входят в тройку факторов, которые к 2100 году за счет изменения свойств субстрата приведут к глобальному изменению биоразнообразия естественных экосистем [25]. В этой связи целью нашего исследования стало изучение состава и свойств атмосферных выпадений $\mathrm{N}_{\text {мин }}$ в лесах промышленного региона (г. Ижевск) и оценка взаимосвязи между поступлением этого загрязнителя, свойствами почв и структурой наземной растительности.

\section{МАТЕРИАЛЫ И МЕТОДЫ}

На территории города Ижевска и пограничном с ним Завьяловском районе (УР) были изучены хвойные и лиственные леса на дерново-подзолистой почве (Umbric Albeluvisols, WRB 2014). Для исследования выбирали репрезентативные ключевые участки $(\mathrm{n}=21)$ в лесах разного типа и уровня антропогенной нагрузки (функциональной зоны города, близость к промышленным источни- кам азота и автодорогам, розы ветров и т.п.), на которых проводили: 1) оценку состава и уровня атмосферных выпадений $\mathrm{N}_{\text {мин }} ; 2$ ) анализ химических свойств почвы; 3) исследование структуры напочвенного покрова лесов (рис. 1).

С целью определения состава и свойств атмосферных выпадений $\mathrm{N}_{\text {мин }}$ (аммонийная $\left(\mathrm{N}_{-} \mathrm{NH}_{4}\right)$ и нитратная $\left(\mathrm{N}-\mathrm{NO}_{3}\right)$ формы) на исследованной территории была проведена снегосъемка $[1,2]$. Поскольку снеговой покров - это универсальная депонирующая среда, то снегосъемка позволяет оценить влажное и сухое осаждение поллютантов за длительный период времени, так как на территории исследования снег сохраняется до 5 месяцев. Кроме того, в течение зимнего периода загрязняющие вещества из снега не переходят в другие компоненты природной среды, что позволяет уменьшать число точек отбора при оценке геохимического фона [1]. На выбранных ключевых участках в период максимального накопления снега (март 2018 г.) отбирали керны (пластиковый пробоотборник, диаметр 5 см) методом смешанной пробы из 5 повторностей. В полученных снежных образцах методом фенолятгипохлоритной реакции в модификации Кудеярова определяли концентрацию $\mathrm{N}-\mathrm{NH}_{4}$ и $\mathrm{N}-\mathrm{NO}_{3}$. Атмосферные выпадения $\mathrm{N}_{\text {мин }}$ за период накопления снега (декабрь-январь-февраль) рассчитывали по формуле: $\mathrm{N}_{\text {мин }}^{\prime}=\left(\mathrm{N}_{\text {мин }} \times \mathrm{V}\right)^{*} 3$, где $\mathrm{N}_{\text {мин }}^{\prime}-$ выпадение азота за год, кг $\mathrm{N} \mathrm{ra}^{-1} ; \mathrm{N}_{\text {мин }}-$ концентрация азота в талой воде, мг $\mathrm{N}^{-1}, V$ мин объем талой воды с одного участка, л (площадь $100 \mathrm{~cm}^{2}$ ).

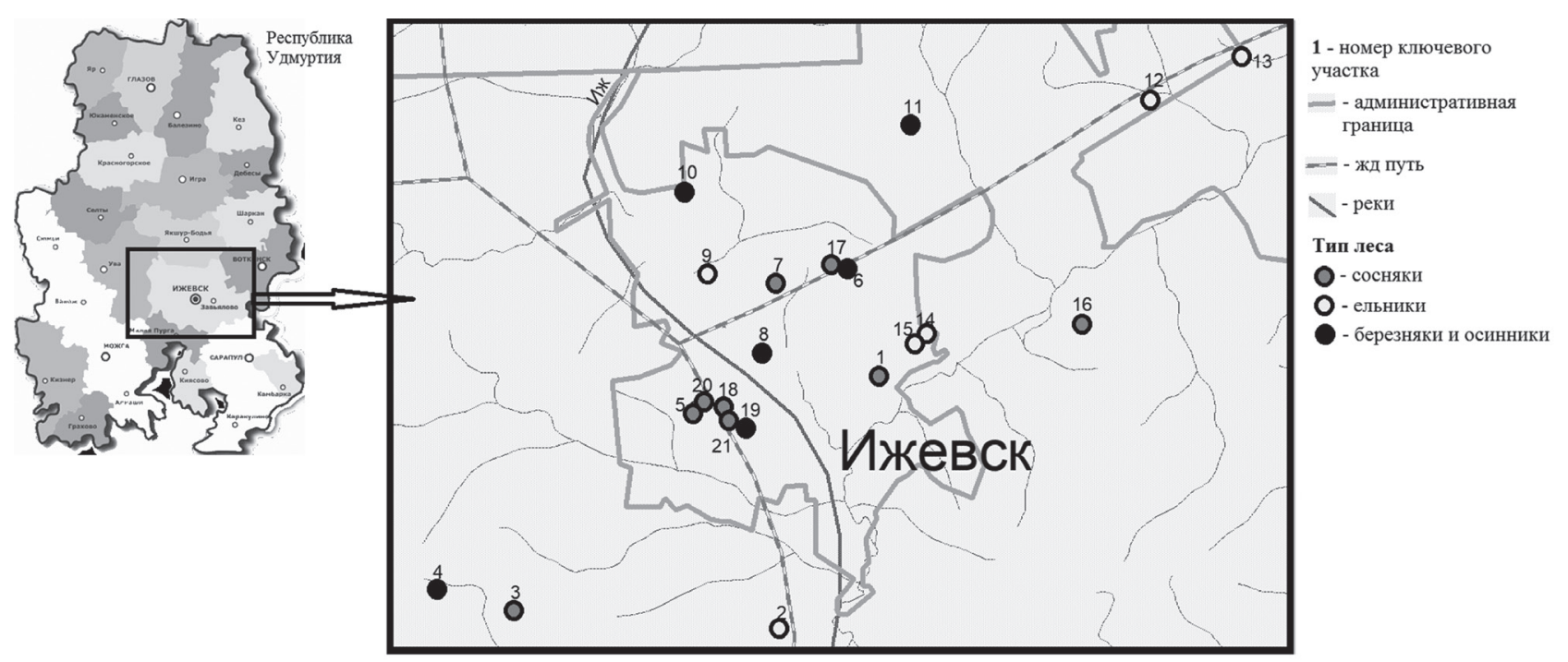

Puc. 1. Расположение ключевых участков на территории Ижевского и Завьяловского районов, Республика Удмуртия, Россия

[Fig. 1. Location of thekey sites withinIzhevsky and Zavyalovsky districts, Republic of Udmurtia, Russia] 
Для идентификации изменений геохимических свойств почвы на тех же ключевых участках, где проводили снегосъемку, в августе 2018 года отбирали смешанный образец (методом конверта, в 5-кратной повторности, ГОСТ 17.4.4.02-2017) из слоя 0-20 см, который характеризуется максимальной насыщенностью корневыми системами растений. В связи с полифункциональностью действия азота в почве изучали параметры, отражающие ее питательные условия и кислотные свойства, а также для снятия вопроса о стрессе растений в городской среде измеряли содержание тяжелых металлов. Так, в образцах почвы определяли содержание $\mathrm{N}_{-} \mathrm{NH}_{4}$ и $\mathrm{N}-\mathrm{NO}_{3}$ (методом фенолятгипохлоритной реакции, ГОСТ № 29313-92), общего углерода $(\mathrm{C})$ и общего азота $(\mathrm{N})$ (методом сухого сжигания в токе кислорода, Elementar Vario EL III), $\mathrm{P}_{2} \mathrm{O}_{5}$ и тяжелых металлов $(\mathrm{Cd}, \mathrm{Pb}, \mathrm{Zn}, \mathrm{Cu}, \mathrm{Ni})$ (рентген-флуоресцентным методом), значение $\mathrm{pH}_{\text {вод }}$ (почва:вода $=1: 2.5$ ). Рассчитывали соотношения в почве $\mathrm{C} / \mathrm{N}$, которое отражает скорость процессов минерализации органического вещества.

В конце периода вегетации (август 2018 г.) на тех же участках случайным методом выбирали

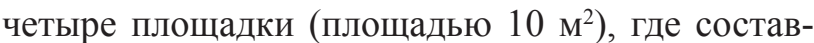
ляли список видов сосудистых растений и их обилие-покрытие по шкале Браун-Бланке. Трофические условия природных экосистем отражает плотность популяции видов-индикаторов, которую можно оценить по наличию или отсутствию в напочвенном покрове нетипичных для этой системы растений нитрофилов/олиготрофов [9]. Для характеристики наличия/отсутствия видов индикаторов обеспеченности почвы $\mathrm{N}_{\text {мин }}$, применяли экологическую шкалу Г. Элленберга (анализ в программе EcoScaleWin) [6].

Весной происходит внутрипочвенная фильтрация талых снеговых вод и формируется необходимый для растений запас почвенной влаги на глубине, поэтому концентрация $\mathrm{N}_{\text {мин }}$ в снеге может рассматриваться как показатель обеспеченности его доступными формами для питания растений в начале периода вегетации. Для того чтобы определить воздействие атмосферных выпадений $\mathrm{N}_{\text {мин }}$ на структуру наземной растительности в исследованных лесах сравнивали концентрацию азота в талой воде изученных участков с критическими концентрациями этого элемента для разных трофических групп напочвенного покрова и типов леса. По данным Де Врис с соавторами, критическая концентрация $\mathrm{N}_{\text {мин }}$ приводящая к смене видов в напочвенном покрове и древесном ярусе, составляет для лишайников, мхов и олиготрофных кустарничков 0,2-0,4, мезотрофных кустарничков - 0,6-1,0, злаков - 3, хвойных пород - 2,54,0 , лиственных пород - 3,5-6,5 мг N/л [14].

Статистика. Измерение химических показателей почвы и талой воды (снег) выполняли в двух повторностях, а результаты измерений выражали как среднее \pm стандартное отклонение. Нормальность распределения полученных данных проверяли графически (гистограмма) и критерием Шапиро-Уилка. Для нормализации полученных данных производили логарифмирование. Взаимосвязь между атмосферным выпадением $\mathrm{N}_{\text {мин }}$, свойствами почвы и структурой растений в напочвенном покрове оценивали с помощью анализа главных компонент (ГК), а визуализация его результатов была выполнена в программе Statistica 11.0.

\section{РЕЗУЛЬТАТЫ И ОБСУЖДЕНИЕ}

Содержание $\mathrm{N}^{-\mathrm{NH}_{4}}$ в талой воде составило 0,02-8,4 мг $\mathrm{N}^{-1}$, а N-NO было в 10 раз меньше $\left(0-2,7\right.$ мг $\left.\mathrm{N}^{-1}\right)$. Суммарная концентрация $\mathrm{N}_{\text {мин }}$ в лиственных лесах (осинники + березняки) варьировала от 0,13 до 2,8 мг $\mathrm{N}^{-1}$, а в сосняках и ельниках была 0,09-5,4 и 0,08-8,4 мг $\mathrm{N}^{-1}$ соответственно (данные не показаны). Выявленные концентрации $\mathrm{N}_{\text {мин }}$ в атмосферных осадках превышают в 3 ареалах (№ 9, 11, 15) критические значения для олиготрофных и мезотрофных видов напочвенного покрова, а в 11 ареалах (№ 1, 2, 3, 7, 8, 10, 16, $17,19,20,21)$ эти значения близки к критическим для хвойных пород деревьев.

Содержание $\mathrm{N}_{-} \mathrm{NH}_{4}$ в атмосферных выпадениях составило 0,11-20,6 кг $\mathrm{N} \mathrm{ra}^{-1} /$ год $^{-1}$, а N-NO 5 раз меньше (0-4,9 кг $\mathrm{N} \mathrm{га}^{-1} /$ год $\left.^{-1}\right)$ (рис. 2). Суммарные выпадения $\mathrm{N}_{\text {мин }}$ на территории изученного района варьировали от 0,15 до 20,6 кг $\mathrm{N} \mathrm{ra}^{-1} /$ год $^{-1}$ и самые высокие их значения (выше 9 кг $\mathrm{N} \mathrm{ra}^{-1 /}$ год $\left.{ }^{-1}\right)$ отмечены в промышленном районе города Ижевска. В химическом составе атмосферных выпадений $\mathrm{N}_{\text {мин }}$ было абсолютное преобладание аммонийной формы (особенно в центральной и северной частях исследованной территории).

Дерново-подзолистая почва (0-20 см) изученных лесов характеризуется кислым и нейтральным значениями $\mathrm{pH}(5,6-7,1)$. Содержание С в почве лесов варьировало от 2,6 до $5,8 \%, \mathrm{~N}-0,18$ $0,38 \%$, отношение $\mathrm{C} / \mathrm{N}-14-15$, при чем наиболее высокие значения этих показателей отмечены в центральной и восточной частях города (№ 2 , $6,7,12)$. В изученных почвах содержание $\mathrm{N}_{-} \mathrm{NH}_{4}$ составило 1,1-3,5 мг $\mathrm{N}$ кг ${ }^{-1}$ почвы, а $\mathrm{N}-\mathrm{NO}_{3}$ варьи- 


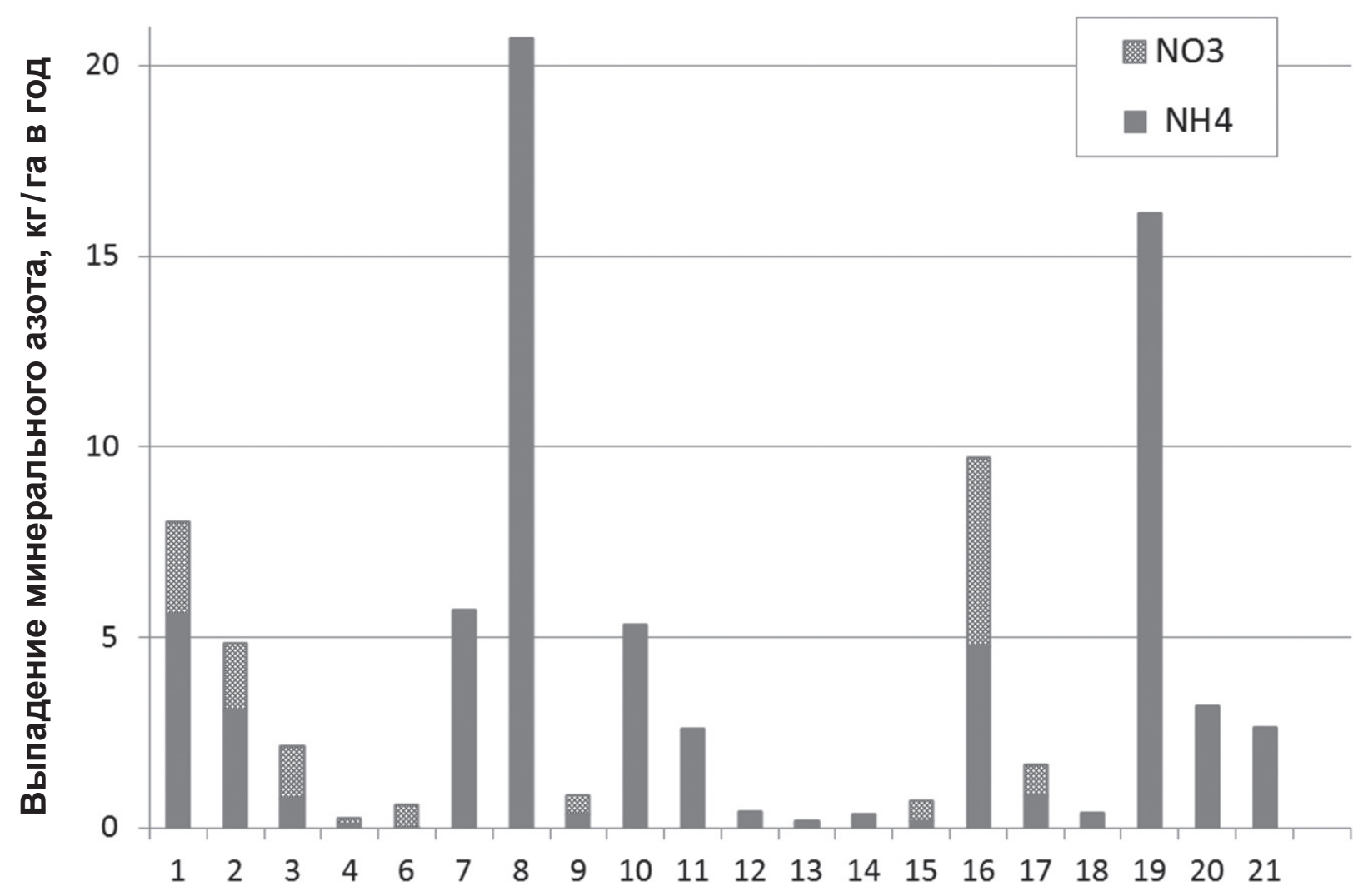

\section{Номер ключевого участка}

Pис. 2. Атмосферные выпадения $\mathrm{N}_{\text {мин }}\left(\mathrm{N}_{-} \mathrm{NH}_{4}\right.$ и $\left.\mathrm{N}-\mathrm{NO}_{3}\right)$ в лесах изученных ключевых участков

[Fig. 2. The atmospheric deposition of $\mathrm{N}_{\min }\left(\mathrm{N}-\mathrm{NH}_{4}\right.$ и $\left.\mathrm{N}-\mathrm{NO}_{3}\right)$ in forests of the studied key sites]

ровало от следовых количеств до 6,5 мг $\mathrm{N}$ кг $\Gamma^{-1}$ почвы. В некоторых лесах (№ $1,3,7,10,15)$ западного и северного районов в почвенном пуле $\mathrm{N}_{\text {мин }}$ преобладали $\mathrm{N}-\mathrm{NO}_{3}$, но в большинстве исследованных экосистем показаны только их следовые концентрации. Содержание фосфора в изученной дерново-подзолистой почве составило 288-1129 мг кГ-1 $\mathrm{P}^{-} \mathrm{P}_{2} \mathrm{O}_{5}$ и наибольшие его значения выявлены в почве центральной части города Ижевска (выше 1000 мг кг-1 $\mathrm{P}^{-} \mathrm{P}_{2} \mathrm{O}_{5}$ ). Содержание в изученной почве валовых форм $\mathrm{Cd}, \mathrm{Pb}, \mathrm{Zn}, \mathrm{Cu}$ и Ni coставило соответственно 0-2,5 мг/кг, 0-132,5 мг/кг, 20,1-319,0 мг/кг, 0,3-91,1 мг/кг и 23,5-102,7 мг/кг (рис. 3), что согласуется с нормами ОДК, а превышение отмечено только в почве сосняка в Завьяловском лесничестве (№ 21).

Напочвенный покров исследованных ареалов был представлен бореально-неморальными ассоциациями. Наибольшее обилие (>3 по шкале Браун-Бланке) в травяном ярусе изученных ареалов показали Aegopodium podagraria L., Stellaria holostea L., Oxalis acetosella L., Equisetum sylvaticum L., Fragaria vesca L., Urtica dioica L, Filipendula ulmaria (L.) Maxim., Bromopsis inermis (Leyss.) Holub, Galium boreale L., Lathyrus vernus (L.) Bernh. В центральной и восточной частях региона исследования в напочвенном покрове преобладали виды Urtica dioica L., Chelidonium majus L., Pteridium aquilinum (L.) Kuhn, Aegopodium podagraria L., Fragaria vesca L., Stellaria holostea L., Oxalis acetosella L. В то время как в западной, более удаленной от городской черты территории, преобладали Asarum europaeum L., Dactylis glomerata L., Aegopodium podagraria L., Anemonoides altaica Holub, Filipendula ulmaria (L.) Maxim.

Анализ распределения видов напочвенного покрова по экологической шкале обеспеченности почв азотом Г. Элленберга показал очень сильную пространственную вариабельность, которая в большей степени зависела от географической приуроченности, чем от типа леса. Для изученных лесов богатые азотом местообитания, где олиготрофные растения встречаются в виде исключения (балл по шкале 7), отмечены в центральной и восточной частях региона исследования (там же выявлены наиболее высокие уровни атмосферных 


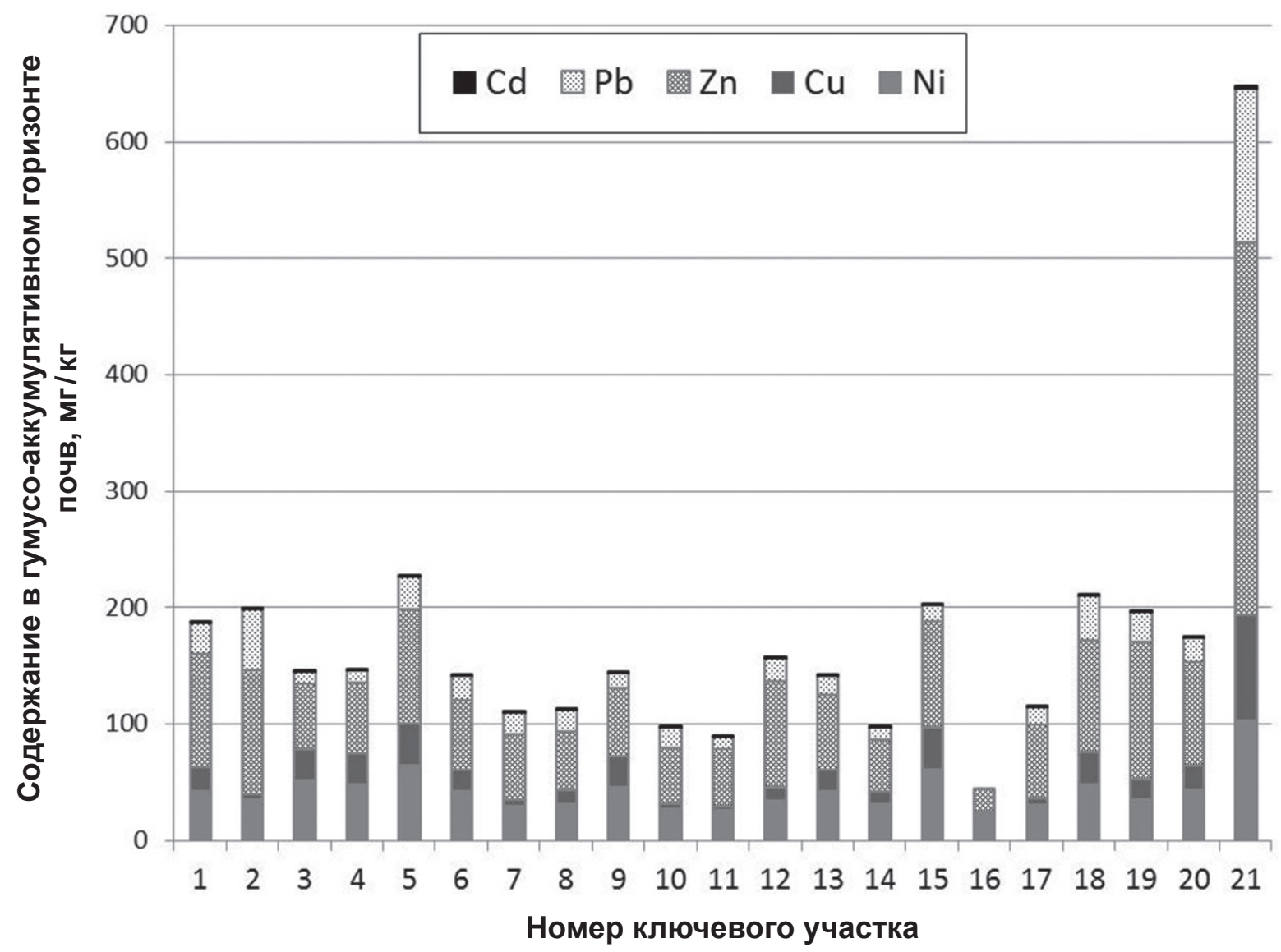

Puc. 3. Содержание тяжёлых металлов в дерново-подзолистой почве изученных лесов

[Fig. 3. The content of heavy metals in the sod-podzolic soil of the studied forests]

выпадений $\mathrm{N}_{\text {мин }}$ ). Большее число исследованных лесов идентифицировано по данной шкале как переходные от умеренно обеспеченных до богатых азотом почв (баллов 5-6). В западном и северном районах встречались местообитания переходные к обедненным почвенным азотом (балл 4).

Экспериментальные данные по атмосферному выпадению $\mathrm{N}_{\text {мин }}$ химическому составу почв и баллам обеспеченности почвы азотом по экологической шкале Г. Элленберга для изученных лесов (21 точка, 12 показателей) были проанализированы методом ГК. Выявлено, что уровень выпадений $\mathrm{N}_{\text {мин }}$, содержание в почве $\mathrm{N}-\mathrm{NO}_{3}, \mathrm{P}_{2} \mathrm{P}_{2} \mathrm{O}_{5}, \mathrm{Cd}$, $\mathrm{Pb}, \mathrm{Zn}, \mathrm{Cu}, \mathrm{Ni}$ и балл по экологической шкале обеспеченности почв минеральным азотом Г. Элленберга вносили наибольший вклад в первую ось, а содержание в почве $\mathrm{N}_{-} \mathrm{NH}_{4}$ и ее $\mathrm{pH}$ во вторую $\left(\mathrm{r}^{2}=0,50-0,70\right)$ (рис. 4). Распределение изученных параметров вдоль первой оси выявило весьма четкую их дифференциацию в градиенте увеличения выпадений $\mathrm{N}_{\text {мин. }}$

В изученных лесах в химическом составе атмосферных выпадений $\mathrm{N}_{\text {мин }}$ преобладал $\mathrm{N}^{-\mathrm{NH}_{4}}$. Повышенная концентрация $\mathrm{N}-\mathrm{NO}_{3}$ отмечена на нескольких участках, расположенных в промышленном районе города Ижевска. Исследования, проведенные в Китае, Индии, Хорватии и России показали, что преобладание $\mathrm{N}_{-} \mathrm{NO}_{3}$ в атмосферных выпадениях характерно для регионов с интенсивной урбанизацией, промышленностью и автотранспортом, а $\mathrm{N}_{-} \mathrm{NH}_{4}-$ в сельскохозяйственных районах $[4,27,30]$. Увеличение аммония в атмосферных выпадениях так же отмечено на лесных территориях, что является результатом увеличения эмиссией при пожарах и разложении большого количества биомассы $[21,24]$.

В изученных почвах в пуле $\mathrm{N}_{\text {мин }}$ преобладал $\mathrm{N}-\mathrm{NH}_{4}$, однако в некоторых лесах было установлено более высокое содержание $\mathrm{N}-\mathrm{NO}_{3}$. В процессе минерализации аммиак быстро освобождается из органических соединений и закрепляется в субстрате, что снижает его содержание в водорастворимом состоянии (в виде нитратов). В конце периода вегетации в лесных почвах пул $\mathrm{N}_{\text {мин }}$ в основном представлен аммонием $[7,8]$. Появление в конце периода вегетации в почве лесов $\mathrm{N}-\mathrm{NO}_{3}$ указывает на избыток поступления азота в экосистему и, чаще всего, 


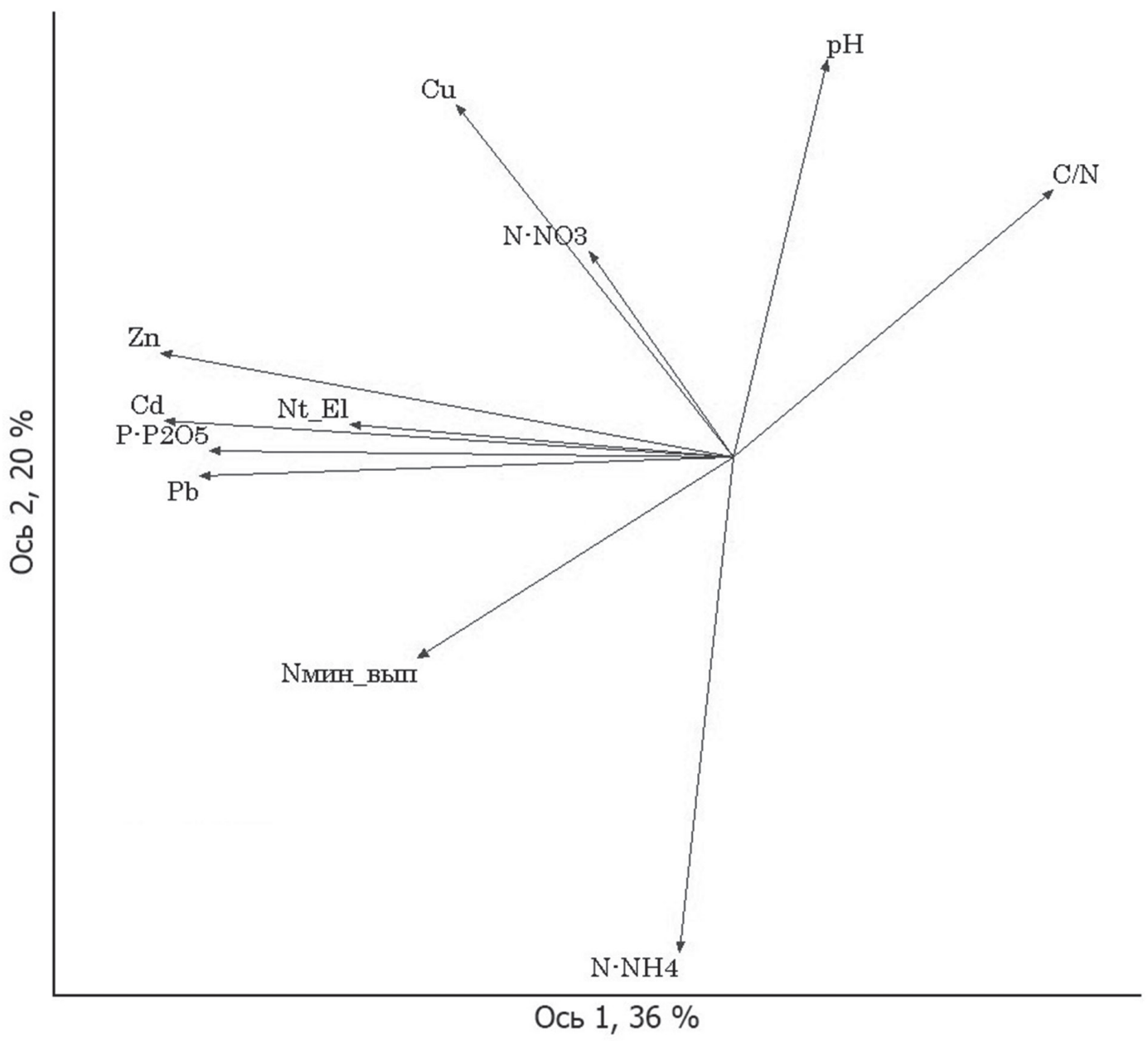

Puc.4. Корреляционная диаграмма (анализ ГК) изученных свойств лесов для выбранных ключевых участков [Fig 4. Correlation diagram (Principal Component Analysis) of the forest studied properties of the selected key areas]

это связано с антропогенным фактором, в том числе с увеличением атмосферных выпадений $[17,23]$. В связи с тем, что нитраты подкисляют почву, снижение в ней рН определяет потерю основных катионов [18], а также может привести к увеличению в ней содержания свободных $\mathrm{Al}_{3+}$ и $\mathrm{Cd}[10,19]$.

Методом ГК было выявлено две группы факторов, коррелирующих между собой. Первую группу (31 \% объясненной вариации значений) составляют уровень выпадений $\mathrm{N}_{\text {мин }}$, содержание в почве $\mathrm{N}_{-} \mathrm{NO}_{3}, \mathrm{P}_{2} \mathrm{P}_{2} \mathrm{O}_{5}, \mathrm{Cd}, \mathrm{Pb}, \mathrm{Zn}, \mathrm{Cu}, \mathrm{Ni}$ и балл по экологической шкале обеспеченности почв минеральным азотом Г. Элленберга (рис. 4). Другими исследователями показано - при увеличении атмосферных выпадений $\mathrm{N}_{\text {мин }}$ в естественных лесах происходит эвтрофикация (повышения питательного статуса) почв, а это приводит к резкому росту первичной биологической продукции фитоценозов $[11,14]$ и изменению процесса минерализации органического вещества [12]. В изученных экосистемах на изменение пи- тательного статуса в сторону эвтрофикации указывает наличие в почвенном пуле $\mathrm{N}-\mathrm{NO}_{3}$ и высокие значения $\mathrm{P}_{2} \mathrm{P}_{2} \mathrm{O}_{5}$. Увеличение питательного статуса субстрата определяет резкий рост видов растений, которые предпочитают обогащенные азотом почвы (нитрофилы) [29]. Данный факт подтвердился в результате нашего исследования, где богатые азотом местообитания, в которых олиготрофные растения, встречающиеся в виде исключения (балл по шкале 7), выявлены в центральной и восточной частях региона исследования, где определены наиболее высокие уровни выпадений $\mathrm{N}_{\text {мин }}$. На территории исследования выявлены значительные концентрации $\mathrm{N}_{\text {мин }}$ в атмосферных осадках, превышающие в 3 ареалах критические значения для олиготрофных и мезотрофных видов напочвенного покрова, а в 11 ареалах эти значения близки к критическим для хвойных пород. Такая ситуация создает угрозу существования данным видам пород при сохранении, а особенно при увеличении современных уровней выпадений $\mathrm{N}_{\text {мин }}$. 


\section{ЗАКЛЮЧЕНИЕ}

В результате наших исследований выявлено, что в лесах города Ижевска и его окрестностей поступление $\mathrm{N}_{\text {мин }}$ с атмосферными выпадениями составляет 0,15-20,6 кг $\mathrm{N} \mathrm{ra}^{-1} /$ год $^{-1}$. Оцененные различия химического состава дерново-подзолистых почв изученного региона указывают на увеличение в них питательных элементов, которое, в свою очередь, определяет изменение в структуре наземной растительности и проявляется в преобладании нитрофильных видов. На некоторых ключевых участках концентрации $\mathrm{N}_{\text {мин }}$ в атмосферных осадках превышают критические значения для олиготрофных и мезотрофных видов напочвенного покрова, что в дальнейшем необходимо учитывать при проведении природоохранных мероприятий в регионе.

\section{СПИСОК ЛИТЕРАТУРЫ}

1. Глазовский Н.Ф., Злобина А.И., Учватов В.П. Химический состав снежного покрова некоторых районов Верхнеокского бассейна // Региональный экологический мониторинг, 1983, с. 67-86.

2. Захарова М. В. Оценка погрешностей данных наблюдений за состоянием загрязнения воздуха // Becmник ВГУ. Серия: География. Геоэкология, 2019, №2, c. 65-72. DOI: $10.17308 /$ geo.2019.2/2304.

3. Крамер П.Д., Козловский Т.Т. Физиология древесных растений. Москва: Лесн. пром-ть, 1983. 464 с.

4. Кудреватых И.Ю. Оценка взаимосвязи между атмосферным выпадением минерального азота и растительностью в лесных экосистемах // Известия РАН. Сер. Биол., 2017, № 2, с. 181-189. DOI: 10.1134/ S106235901702008X.

5. О состоянии и об охране окружающей среды Удмуртской Республики в 2016 г.: Государственный доклад. Ижевск, 2017. 283 с.

6. Смирнов В.Э., Ханина Л.Г., Бобровский М.В. Обоснование системы эколого-ценотических групп видов растений лесной зоны Европейской России на основе экологических шкал, геоботанических описаний и статистического анализа // Бюл. МОИП. Сер. Биологическая, 2006., т. 111, № 2, с. 36-47.

7. Солдатова Е.А., Пургина Д.В. Поведение соединений азота и их трансформация в системе почва - подземные воды сельскохозяйственных ландшафтов Западной Сибири // Вестник ВГУ. Серия: География. Геоэкология, 2020, № 4, с. 32-43. DOI: 10.17308/ geo.2020.4/3063.

8. Федорец Н.Г., Бахмет О.Н. Экологические особенности трансформации соединений углерода и азоmа в лесных почвах, Петрозаводск: Карельский научный центр РАН, 2003. 240 с.

9. Bertills U., Näsholm T. Effects of Nitrogen Deposition on Forest Ecosystems. Swedish Environmental Protection Agency, Trelleborg: Printed Berlings Skogs, 2000. 160 p.
10. Binkley D., Högberga P. Tamm Review: Revisiting the influence of nitrogen deposition on Swedish forests // Forest Ecology and Management, 2016, vol. 368, pp. 222239. DOI: $10.1016 /$ j.foreco.2016.02.035.

11. Bobbink R., Hicks K., Galloway J. et al. Global assessment of nitrogen deposition effects on terrestrial plant diversity: A synthesis // Ecological Applications, 2010, vol. 20, pp. 30-59.

12. Cape J.N., Tang Y.S., González-Benítez J. et al. Organic nitrogen in precipitation across Europe // Biogeosciences, 2012, vol. 9, pp. 4401-4409. DOI: $10.5194 /$ bg-9-4401-2012.

13. Chen S.-P., Wang C.-H., Lin W.-D. et al. Air quality impacted by local pollution sources and beyond Using a prominent petro-industrial complex as a study case // Environmental Pollution, 2018, vol. 236, pp. 699-705. DOI: 10.1016/j.envpol.2018.01.091.

14. De Vries W., Kros H., Reinds G.J. et al. Developments in deriving critical limits and modelling critical loads of nitrogen for terrestrial ecosystems in Europe. Alterra - rapport 1382. Alterra, 2007. 206 p.

15. Galloway J.N., Townsend A.R., Erisman J.W et al. Transformation of the nitrogen cycle: Recent trends, questions and potential solutions // Science, 2008, vol. 320, pp. 889-892. DOI: $10.1126 /$ science. 1136674.

16. Houa X., Zhana X., Zhoua F. et al. Detection and attribution of nitrogen runoff trend in China's croplands // Environmental Pollution, 2018, vol. 234, pp. 270-278. DOI: 10.1016/j.envpol.2017.11.052.

17. LeBauer D.S., Treseder K.K. Nitrogen limitation of net primary productivity in terrestrial ecosystems is globally distributed // Ecology, 2008, vol. 89, pp. 371-380. DOI: 10.1890/06-2057.1.

18. Lui S., Lin F., Wu S. et al. A meta-analysis of fertilizer-induced soil $\mathrm{NO}$ and combined $\mathrm{NO}+\mathrm{N}_{2} \mathrm{O}$ emissions // Global Change Biology, 2017, vol. 23, pp. 2520-2532. DOI: $10.1111 / \mathrm{gcb} .13485$.

19. MacDonald J.A., Dise N.B., Matzner E., Armbruster M. et al. Nitrogen input together with ecosystem nitrogen enrichment predict nitrate leaching from European forests // Global Change Biology, 2002, vol. 8, pp. 1028-1033. DOI: 10.1046/j.1365-2486.2002.00532.x.

20. McDonnell T.C., Belyazid S., Sullivan T.J. et al. Vegetation dynamics associated with changes in atmospheric nitrogen deposition and climate in hardwood forests of Shenandoah and Great Smoky Mountains National Parks, USA // Environmental Pollution, 2018, vol. 237, pp. 662-674. DOI: 10.1016/j.envpol.2018.01.112.

21. Nave L.E., Vance E.D., Swanston C.W., Curtis P.S. Fire effects on temperate forest soil C and N storage // Ecological Applications, 2011, vol. 21, iss. 4, pp. 1189-1201. DOI: 10.1890/10-0660.1.

22. Satyanarayana J., Reddy L.A. K., Kulshrestha M. J. et al. Chemical composition of rain water and influence of airmass trajectories at a rural site in an ecological sensitive area of Western Ghats (India) // Journal of Atmospheric Chemistry, 2010, vol. 66, pp. 101-116. DOI: 10.1007/ s10874-011-9193-2. 
23. Oulehle F., Tahovská K., Chuman T. et al. Comparison of the impacts of acid and nitrogen additions on carbon fluxes in European conifer and broadleaf forests // Environmental Pollution, 2018, vol. 238, pp. 884-893. DOI: 10.1016/j.envpol.2018.03.081.

24. Rao L.E., Parker D.R., Bytnerowicz A., Allen E.B. Nitrogen mineralization across an atmospheric nitrogen deposition gradient in Southern California deserts // Journal of Arid Environments, 2009, vol. 73, pp. 920-950. DOI: 10.1016/j.jaridenv.2009.04.007.

25. Sala O.E., Chapin F.S., Armesto J.J. et al. Biodiversity - global biodiversity scenarios for the year 2100 // Science, 2000, vol. 287, pp. 1770-1774. DOI: $10.1126 /$ science.287.5459.1770.

26. Shi L., Zhang H., Liu T. et al. Consistent effects of canopy vs. understory nitrogen addition on the soil exchangeable cations and microbial community in two contrasting forests // Science of the Total Environment, 2016, vol. 553, pp. 349-357. DOI: 10.1016/j. scitotenv.2016.02.100.

27. Sutton M.A., Mason K.E., Sheppard L.J. et al. Nitrogen Deposition, Critical Loads and Biodiversity. Springer, 2014. $535 \mathrm{p}$.
28. Tian P., Liu S., Wang Q., Sun T., Blagodatskaya E. Organic N deposition favours soil C sequestration by decreasing priming effect // Plant and Soil, 2019, vol. 445, iss. 1-2, pp. 439-451. DOI: $10.1007 /$ s11104-01904331-3.

29. Van Dobben V.H., De Vries W. Relation between forest vegetation, atmospheric deposition and site conditions at regional and European scale // Environmental Pollution, 2010, vol. 158, pp. 921-933. DOI: 10.1016/j. envpol.2009.09.015.

30. Wang X., Zou C., Gao X. et al. Nitrous oxide emissions in Chinese vegetable systems: A meta - analysis // Environmental Pollution, 2018, vol. 239, pp. 375-383. DOI: 10.1016/j.envpol.2018.03.090.

Конфликт интересов: Авторы декларируют отсутствие явных и потенциальных конфликтов интересов, связанных с публикацией настоящей статьи.

Поступила в редакцию 02.09.2020 Принята к публикации 28.05.2021

UDC 504.064.2

ISSN 1609-0683

DOI: https://doi.org/10.17308/geo.2021.2/3441

\title{
Interaction Between Atmospheric Deposition of Mineral Nitrogen, Structure of Ground Cover and Soil Properties in Forests of Izhevsk
}

\author{
I.Yu. Kudrevatykh ${ }^{1 凶}$, G. R. Platunova ${ }^{2}$ \\ ${ }^{I}$ Institute of Physicochemical and Biological Problems of Soil Science of the Russian Academy of Sciences, \\ Russian Federation \\ (2 Bldg., 2, Institutskaya St., Pushchino, Moscow Region, 142290) \\ ${ }^{2}$ Udmurt State University, Russian Federation \\ (1, Universitetskaya St., Izhevsk, 426034)
}

\begin{abstract}
The aim is to study atmospheric deposition of mineral nitrogen $\left(\mathrm{N}_{\min }\right)$ in the forests of an industrial region to assess the relationship between these ones, changes in soil properties and the structure of terrestrial vegetation. The relationship between the studied parameters was assessed using principal component analysis.

Materials and methods. The coniferous and deciduous forests $(\mathrm{n}=21)$ on sod-podzolic soil were studied in theIzhevsk City and Zavyalovsky districtof the Udmurt Republic. The studies were conducted based on the assessment of atmospheric deposition of $\mathrm{N}_{\min }$ by snow survey, soil sampling from the humus-accumulative horizon and geobotanical description of vegetation. The content of ammonium and nitrate was determined in the snow and soil. The contents of total organic carbon, total nitrogen, $\mathrm{P}_{2} \mathrm{O}_{5}, \mathrm{Cd}, \mathrm{Pb}, \mathrm{Zn}, \mathrm{Cu}, \mathrm{Ni}$ and $\mathrm{pH}$ were determined in the soil.
\end{abstract}

Results and discussion. The atmospheric deposition of $\mathrm{N}_{\min }$ in the study area ranged from 0,15 to 20,6 $\mathrm{kg} \mathrm{N} \mathrm{ha}^{-1} /$ year $^{-1}$, in which the ammonium form prevailed. Analysis of main components showed a correlation

(C) Kudrevatykh I.Yu., Platunova G. R., 2021

$\triangle$ Irina Yu. Kudrevatykh, e-mail: averkieva.irina@yandex.ru

The content is available under Creative Commons Attribution 4.0 License. 
between the atmospheric deposition of $\mathrm{N}_{\text {min }}$, the content of $\mathrm{N}_{-} \mathrm{NO}_{3}, \mathrm{P}-\mathrm{P}_{2} \mathrm{O}_{5}, \mathrm{Cd}, \mathrm{Pb}, \mathrm{Zn}, \mathrm{Cu}, \mathrm{Ni}$ in the soil and G. Ellenberg's score on the ecological scale of soil supply with mineral nitrogen.

Key words: forests, nitrogen pollution, soil cover, chemical properties of soils.

Funding: This study was carried out in accordance with the government's assignment No. 0191-2019-048.

For citation: Kudrevatykh I.Yu., Platunova G.R. Interaction Between Atmospheric Deposition of Mineral Nitrogen, Structure of Ground Cover and Soil Properties in Forests of Izhevsk. Vestnik Voronezskogo gosudarstvennogo universiteta. Seria: Geografia. Geoekologia, 2021, no. 2, pp. 3-12. (In Russ.) DOI: https://doi.org/10.17308/geo.2021.2/3441

\section{REFERENCES}

1. Glazovskij N.F., Zlobina A.I., Uchvatov V.P. Himicheskij sostav snezhnogo pokrova nekotoryh rajonov Verhneokskogo bassejna [The chemical composition of the snow cover in some areas of the Upper Oka basin]. Regionalnyj Ekologicheskij monitoring, 1983, pp. 67-86. (In Russ.)

2. Zaharova M.V. Ocenka pogreshnostej dannyh nabljudenij za sostojaniem zagrjaznenija vozduha [Estimation of errors in the data of observations of the state of air pollution]. Vestnik Voronezskogo gosudarstvennogo universiteta. Seria: Geografia. Geoekologia, 2019, no. 2, pp. 65-72. DOI: 10.17308/geo.2019.2/2304. (In Russ.)

3. Kramer P. D., Kozlovskij T. T. Fiziologija drevesnyh rastenij [Physiology of woody plants]. Moskow: Lesn. prom-tj, 1983. 464 p. (In Russ.)

4. Kudrevatyh I. Ju. Ocenka vzaimosvjazi mezhdu atmosfernym vypadeniem mineralnogo azota i rastitelnostju v lesnyh ekosistemah [Assessment of the relationship between atmospheric mineral nitrogen deposition and vegetation in forest ecosystems]. Izvestija RAN. Ser. Biol., 2017, no. 2, pp. 181-189. DOI: 10.1134/S106235901702008X. (In Russ.)

5. O sostojanii i ob ohrane okruzhajuschej sredy Udmurtskoj Respubliki v 2016 g.: Gosudarstvennyj doklad [On the state and protection of the environment of the Udmurt Republic in 2016: State report]. Izhevsk, 2017. 283 p. (In Russ.)

6. Smirnov V. E., Hanina L. G., Bobrovskij M. V. Obosnovanie sistemy ekologo-cenoticheskih grupp vidov rastenij lesnoj zony Evropejskoj Rossii na osnove ekologicheskih shkal, geobotanicheskih opisanij i statisticheskogo analiza [Substantiation of the system of ecological-cenotic groups of plant species in the forest zone of European Russia on the basis of ecological scales, geobotanical descriptions and statistical analysis]. Bjul. MOIP. Ser. Biologicheskaja, 2006., vol. 111, no. 2, pp. 36-47. (In Russ.)

7. Soldatova E.A., Purgina D.V. Povedenie soedinenij azota $\mathrm{i}$ ih transformacija $\mathrm{v}$ sisteme pochva - podzemnye vody selskohozjajstvennyh landshaftov Zapadnoj Sibiri [Behavior of nitrogen compounds and their transformation in the soil - groundwater system of agricultural landscapes of Western Siberia]. Vestnik Voronezskogo gosudarstvennogo universiteta. Seria: Geografia. Geoekologia, 2020, no. 4, pp. 32-43. DOI: 10.17308/geo.2020.4/3063. (In Russ.)

8. Fedorec N.G., Bahmet O.N. Ekologicheskie osobennosti transformacii soedinenij ugleroda $i$ azota $v$ lesnyh pochvah [Ecological features of the transformation of carbon and nitrogen compounds in forest soils]. Petrozavodsk: Karelskij nauchnyj centr RAN, 2003. 240 p. (In Russ.)
9. Bertills U., Näsholm T. Effects of Nitrogen Deposition on Forest Ecosystems. Swedish Environmental Protection Agency, Trelleborg: Printed Berlings Skogs, 2000. 160 p.

10. Binkley D., Högberga P. Tamm Review: Revisiting the influence of nitrogen deposition on Swedish forests. Forest Ecology and Management, 2016, vol. 368, pp. 222-239. DOI: 10.1016/j.foreco.2016.02.035.

11. Bobbink R., Hicks K., Galloway J. et al. Global assessment of nitrogen deposition effects on terrestrial plant diversity: A synthesis. Ecological Applications, 2010, vol. 20, pp. 30-59.

12. Cape J.N., Tang Y.S., González-Benítez J. et al. Organic nitrogen in precipitation across Europe. Biogeosciences, 2012, vol. 9, pp. 4401-4409. DOI: 10.5194/bg9-4401-2012.

13. Chen S.-P., Wang C.-H., Lin W.-D. et al. Air quality impacted by local pollution sources and beyond - Using a prominent petro-industrial complex as a study case. Environmental Pollution, 2018, vol. 236, pp. 699-705. DOI: 10.1016/j.envpol.2018.01.091.

14. De Vries W., Kros H., Reinds G.J. et al. Developments in deriving critical limits and modelling critical loads of nitrogen for terrestrial ecosystems in Europe. Alterra-rapport 1382. Alterra, 2007. $206 \mathrm{p}$.

15. Galloway J.N., Townsend A.R., Erisman J.W et al. Transformation of the nitrogen cycle: Recent trends, questions and potential solutions. Science, 2008, vol. 320, pp. 889-892. DOI: $10.1126 /$ science. 1136674.

16. Houa X., Zhana X., Zhoua F. et al. Detection and attribution of nitrogen runoff trend in China's croplands. Environmental Pollution, 2018, vol. 234, pp. 270-278. DOI: 10.1016/j.envpol.2017.11.052.

17. LeBauer D.S., Treseder K.K. Nitrogen limitation of net primary productivity in terrestrial ecosystems is globally distributed. Ecology, 2008, vol. 89, pp. 371-380. DOI: 10.1890/06-2057.1.

18. Lui S., Lin F., Wu S. et al. A meta-analysis of fertilizer-induced soil $\mathrm{NO}$ and combined $\mathrm{NO}+\mathrm{N}_{2} \mathrm{O}$ emissions. Global Change Biology, 2017, vol. 23, pp. 2520-2532. DOI: $10.1111 / \mathrm{gcb} .13485$.

19. MacDonald J.A., Dise N.B., Matzner E., Armbruster M. et al. Nitrogen input together with ecosystem nitrogen enrichment predict nitrate leaching from European forests. Global Change Biology, 2002, vol. 8, pp. 10281033. DOI: 10.1046/j.1365-2486.2002.00532.x.

20. McDonnell T. C., Belyazid S., Sullivan T. J. et al. Vegetation dynamics associated with changes in atmospheric nitrogen deposition and climate in hardwood for- 
ests of Shenandoah and Great Smoky Mountains National Parks, USA. Environmental Pollution, 2018, vol. 237, pp. 662-674. DOI: 10.1016/j.envpol.2018.01.112.

21. Nave L. E., Vance E. D., Swanston C. W., Curtis P. S. Fire effects on temperate forest soil $\mathrm{C}$ and $\mathrm{N}$ storage. Ecological Applications, 2011, vol. 21, iss. 4, pp. 1189-1201. DOI: 10.1890/10-0660.1.

22. Satyanarayana J., Reddy L.A. K., Kulshrestha M. J. et al. Chemical composition of rain water and influence of airmass trajectories at a rural site in an ecological sensitive area of Western Ghats (India). Journal of Atmospheric Chemistry, 2010, vol. 66, pp. 101-116. DOI: 10.1007/ s10874-011-9193-2.

23. Oulehle F., Tahovská K., Chuman T. et al. Comparison of the impacts of acid and nitrogen additions on carbon fluxes in European conifer and broadleaf forests. Environmental Pollution, 2018, vol. 238, pp. 884-893. DOI: 10.1016/j.envpol.2018.03.081.

24. Rao L.E., Parker D.R., Bytnerowicz A., Allen E. B. Nitrogen mineralization across an atmospheric nitrogen deposition gradient in Southern California deserts. Journal of Arid Environments, 2009, vol. 73, pp. 920-950. DOI: 10.1016/j.jaridenv.2009.04.007.

25. Sala O.E., Chapin F. S., Armesto J. J. et al. Biodiversity - global biodiversity scenarios for the year 2100 . Science, 2000, vol. 287, pp. 1770-1774. DOI: $10.1126 /$ science.287.5459.1770.

\section{Кудреватых Ирина Юрьевна}

кандидат биологических наук, научный сотрудник лаборатории геохимии и минералогии почв Института физико-химических и биологических проблем почвоведения Российской академии наук, Московская обл., г. Пущино, Российская Федерация, ORCID: 00000002-8588-1972, e-mail: averkieva25@rambler.ru

Платунова Гузель Рашидовна

кандидат биологических наук, доцент кафедры экологии и природопользования Удмуртского государственного университета, г. Ижевск, Российская Федерация, ORCID: 0000-0003-2626-0823, e-mail: dyukina-guzel@yandex.ru
26. Shi L., Zhang H., Liu T. et al. Consistent effects of canopy vs. understory nitrogen addition on the soil exchangeable cations and microbial community in two contrasting forests. Science of the Total Environment, 2016, vol. 553, pp. 349-357. DOI: 10.1016/j.scitotenv.2016.02.100.

27. Sutton M.A., Mason K.E., Sheppard L.J et al. Nitrogen Deposition, Critical Loads and Biodiversity. Springer, 2014. 535 p.

28. Tian P., Liu S., Wang Q., Sun T., Blagodatskaya E. Organic $\mathrm{N}$ deposition favours soil $\mathrm{C}$ sequestration by decreasing priming effect. Plant and Soil, 2019, vol. 445, iss. 1-2, pp. 439-451. DOI: 10.1007/s11104-019-04331-3.

29. Van Dobben V.H., De Vries W. Relation between forest vegetation, atmospheric deposition and site conditions at regional and European scale. Environmental Pollution, 2010, vol. 158, pp. 921-933. DOI: 10.1016/j.envpol.2009.09.015.

30. Wang X., Zou C., Gao X. et al. Nitrous oxide emissions in Chinese vegetable systems: A meta - analysis. Environmental Pollution, 2018, vol. 239, pp. 375-383. DOI: $10.1016 /$ j.envpol.2018.03.090.

Conflict of interests: The authors declare no information of obvious and potential conflicts of interest related to the publication of this article.

Received: 02.09.2020 Accepted: 28.05.2021

Irina Yu. Kudrevatykh

Cand. Sci. (Biol.), Research scientist of the Laboratory Geochemistry and Mineralogy of Soils, Institute of Physicochemical and Biological Problems of Soil Science, Russian Academy of Sciences, Pushchino, Moscow Region, Russian Federation, ORCID: 0000-0002-8588-1972, e-mail: averkieva25@rambler.ru

Guzel R. Platunova

Cand. Sci. (Biol.), Associate Professor of the Department of Ecology and Nature Management, Udmurt State University, Izhevsk, Russian Federation, ORCID: 0000-00032626-0823, e-mail: dyukina-guzel@yandex.ru 